\title{
Ability of extracellular volume imaging to serially measure infarct size compared to LGE within six months after acute myocardial infarction
}

\author{
Martin R Sinn ${ }^{1 *}$, Enver Tahir ${ }^{1}$, Ulf K Radunski ${ }^{2}$, Dennis Säring ${ }^{3}$, Kai Muellerleile ${ }^{2}$, Christian Stehning ${ }^{4}$, Gerhard Adam ${ }^{1}$ \\ , Gunnar Lund ${ }^{1}$
}

From 18th Annual SCMR Scientific Sessions

Nice, France. 4-7 February 2015

\section{Background}

T1 mapping and extracellular volume (ECV) imaging are promising tools to quantify increased extracellular distribution volume of contrast media after myocardial damage. We evaluated the ability of ECV imaging to measure infarct size compared to late gadolinium enhancement (LGE) after acute myocardial infarction (AMI). Additionally, the amount of cellular damage was serially measured by ECV imaging.

\section{Methods}

CMR (1.5 Tesla Philips Achieva) was performed in 11 patients four times after reperfused AMI at baseline (BL) at $10 \pm 7$ days after infarction and at $7.2 \pm 1$.4 weeks (follow-up 1, FU1), $3.4 \pm 0.3$ months (FU2) and $6.5 \pm 0.5$ months (FU3), respectively. T1 quantification was performed before (T1pre) and 15 minutes after (T1post) administration of $0.075 \mathrm{mmol} / \mathrm{kg}$ gadolinium BOPTA on 3 short-axes for ECV calculation using the modified Look-Locker inversion-recovery (MOLLI) sequences. T1 and ECV maps were calculated with a dedicated plug-in written for the OsiriX software. Two experienced observers independently evaluated LGE-CMR as well as T1 mapping using the HeAT-Software applying a threshold method. Size of infarction and areas of prolonged post $\mathrm{T} 1$ or increased ECV was measured using a cutoff $>2 \mathrm{SD}$ of remote normal myocardium.

\section{Results}

Infarct size on LGE images was at BL $26 \pm 8 \% \mathrm{LV}$ and decreased to $21 \pm 10 \% \mathrm{LV}, 18 \pm 10 \% \mathrm{LV}$ and $21 \pm 9 \% \mathrm{LV}$

Department of Diagnostic and Interventional Radiology, University Medical

Center Hamburg-Eppendorf, Hamburg, Germany, Hamburg, Germany

Full list of author information is available at the end of the article

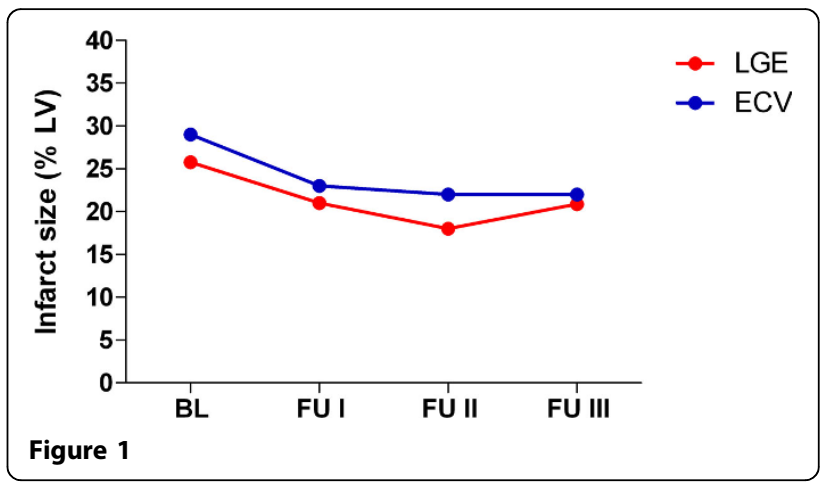

at FU1, FU2 and FU3, respectively (Figure 1). Infarct size obtained by EVC imaging was slightly, but not significantly higher with $29 \pm 10 \% \mathrm{LV}$ at $\mathrm{BL}$ and decreased to $23 \pm 8 \% \mathrm{LV}, 22 \pm 8 \% \mathrm{LV}$ and $22 \pm 9 \% \mathrm{LV}$ at FU1, FU2 and FU3, respectively $(P=$ ns for all time points compared to LGE). ECV was $46 \pm 4 \%$ at BL and increased to $49 \pm 5 \%$ at FU1 $(P<0.05)$ and remained constant at FU2 with $48 \pm 6 \%$ and $50 \pm 12 \%$ at FU3 (Figure 2).

\section{Conclusions}

Similar infarct sizes were measured by LGE and ECV at four consecutive time points after AMI. ECV additionally gave information about the magnitude of cellular damage, which increased during infarct shrinkage. ECV enables to monitor infarct healing after AMI.

\section{Funding}

This study is partially funded by the Deutsche Forschungsgemeinschaft. 


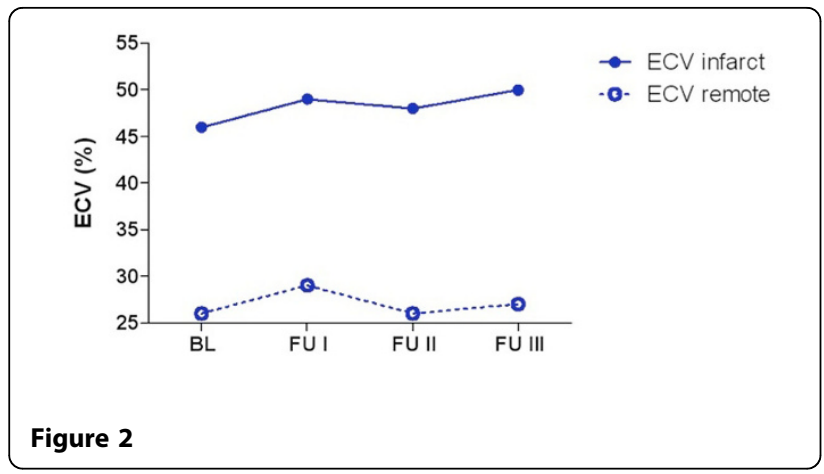

\section{Authors' details}

'Department of Diagnostic and Interventional Radiology, University Medical Center Hamburg-Eppendorf, Hamburg, Germany, Hamburg, Germany. ${ }^{2}$ Departments of Cardiology, University Hospital Eppendorf, Hamburg Germany. ${ }^{3}$ Department of of Computational Neuroscience, University Medical Center Hamburg-Eppendorf, Hamburg, Germany. ${ }^{4}$ Philips Research Europe, Hamburg, Germany.

Published: 3 February 2015

doi:10.1186/1532-429X-17-S1-P112

Cite this article as: Sinn et al: Ability of extracellular volume imaging to serially measure infarct size compared to LGE within six months after acute myocardial infarction. Journal of Cardiovascular Magnetic Resonance 2015 17(Suppl 1):P112.

\section{Submit your next manuscript to BioMed Central} and take full advantage of:

- Convenient online submission

- Thorough peer review

- No space constraints or color figure charges

- Immediate publication on acceptance

- Inclusion in PubMed, CAS, Scopus and Google Scholar

- Research which is freely available for redistribution

Submit your manuscript at www.biomedcentral.com/submit 